\title{
Identification, Synthesis, and Behavioral Activity of 5,11-Dimethylpentacosane, A Novel Sex Pheromone Component of the Greater Wax Moth, Galleria Mellonella (L.)
}

\author{
Glenn P. Svensson • Eylem Akman Gündüz • Natalia Sjöberg • Erik Hedenström • \\ Jean-Marc Lassance • Hong-Lei Wang • Christer Löfstedt • Olle Anderbrant
}

Received: 15 January 2014 /Revised: 7 March 2014 / Accepted: 14 March 2014 /Published online: 2 April 2014

(C) Springer Science+Business Media New York 2014

\begin{abstract}
The greater wax moth, Galleria mellonella (L.), is a serious and widespread pest of the honeybee, Apis mellifera $\mathrm{L}$. In contrast to most moths, for which long-range mate finding is mediated by female-produced sex pheromones, G. mellonella males attract conspecific females over long distances by emitting large amounts of a characteristic scent in combination with bursts of ultrasonic calls. The male scent for this species was previously identified as a blend of nonanal and undecanal. When these compounds were bioassayed, characteristic short-range sexual behavior, including wing fanning, was triggered in conspecific females, but the aldehyde blend failed to elicit attraction over longer distances. We identified, via analysis and synthesis, a third male-specific compound, 5,11-dimethylpentacosane. We show that it acts as a behavioral synergist to the aldehydes. In wind tunnel experiments, very few female moths responded to the aldehyde blend or to 5,11-dimethylpentacosane tested separately, but consistently showed orientation and source contact when a
\end{abstract}

Electronic supplementary material The online version of this article (doi:10.1007/s10886-014-0410-8) contains supplementary material, which is available to authorized users.

G. P. Svensson $(\bowtie) \cdot$ J.-M. Lassance $\cdot$ H.-L. Wang $\cdot$ C. Löfstedt •

O. Anderbrant

Department of Biology, Lund University, 22362 Lund, Sweden

e-mail: glenn.svensson@biol.lu.se

\section{E. A. Gündüz}

Department of Biology, Ondokuz Mayis University, 55139

Kurupelit, Samsun, Turkey

N. Sjöberg • E. Hedenström

Eco-Chemistry, Department of Chemical Engineering, Mid Sweden

University, 85170 Sundsvall, Sweden

Present Address:

J.-M. Lassance

Department of Organismic and Evolutionary Biology, Harvard

University, Cambridge, MA 02138, USA combination of all three compounds was applied. The level of attraction to the three-component mixture was still lower than that to male extract, indicating that the composition of compounds in the synthetic blend is suboptimal, or that additional pheromone components of $G$. mellonella are yet to be identified. The identification of 5,11-dimethylpentacosane is an important step for the development of an efficient longrange attractant that will be integrated with other environmentally safe strategies to reduce damage to beehives caused by wax moths.

Keywords Galleria mellonella $\cdot$ Male pheromone · 5,11-dimethylpentacosane $\cdot$ Electrophysiology $\cdot$ Behavior . Synthesis $\cdot$ Honeybee pest $\cdot$ Lepidoptera

\section{Introduction}

The greater wax moth, Galleria mellonella (L.) (Lepidoptera: Pyralidae: Galleriinae), is an important pest in hives of the honeybee, Apis mellifera L., and occurs throughout the world where honeybees are kept. Strong, active bee colonies generally are less vulnerable to wax moth infestations compared to colonies weakened by pesticide treatments or diseases (Romel et al. 1992). Adult moths emerge in bee colonies, but typically leave to search for mates (Nielsen and Brister 1977). In the evening, when colonies are less protected by bees, mated female wax moths return to enter the colonies to oviposit (Nielsen and Brister 1977). The emerging larvae feed on the wax, pollen, and honey inside hives (Nielsen and Brister 1979), and can cause severe problems for the beekeeping industry. Traditionally, wax moth populations have been controlled with chemical pesticides, but these leave residues in the honey and are discouraged. There is currently no practical 
alternative to chemical fumigation for large-scale control of this pest.

Long-range mate attraction in Lepidoptera is typically mediated by female-released pheromones. Although maleproduced pheromones have been identified in a number of moth species, such signals generally are involved in courtship behaviors at close range (Birch et al. 1990; Lassance and Löfstedt 2009; Phelan 1997). Members of the subfamily Galleriinae, including G. mellonella, the lesser wax moth, Achroia grisella (Fabr.), and the bee moth, Aphomia sociella L., represent rare cases of sex-role reversal, in which males produce a sex pheromone that mediates long-distance mate finding by females. In all three species, males release characteristic scents from specialized forewing glands that can be perceived by the human nose; this pheromonal cue, together with ultrasonic signaling, triggers attraction of females. These moths are parasites on wild social bees, wasps, and bumblebees, and their sensory ecology has been studied in detail (Dahm et al. 1971; Flint and Merkle 1983; Kalinová et al. 2009; Kindl et al. 2011; Spangler 1986, 1987).

The scent produced by G. mellonella males was identified several decades ago as a blend of two short-chain aldehydes, nonanal and undecanal (Leyrer and Monroe 1973; Romel et al. 1992). The electrophysiological responses of females to these aldehydes, as well as biosynthesis of these compounds, have been studied in detail (Payne and Finn 1977; Schmidt and Monroe 1976). Furthermore, laboratory and field studies have evaluated the attractiveness of the aldehyde blend to female G. mellonella. Wind tunnel tests, in which virgin females were released and captured in delta traps within $48 \mathrm{~h}$, indicated that baits containing a 1:1 or 7:3 ratio of undecanal: nonanal was as efficient for attracting females as three caged conspecific males (Flint and Merkle 1983). However, other tests performed in an apiary revealed that a 7:3 ratio of aldehydes was not effective for attracting female moths (Flint and Merkle 1983), indicating that the identification of the G. mellonella sex pheromone was incomplete.

There currently is no synthetic sex attractant available for monitoring G. mellonella populations. Thus, developing an efficient lure for this pest is highly desirable. As a first step in this process, we reinvestigated the male-produced sex pheromone of G. mellonella through chemical, electrophysiological, and behavioral analyses.

\section{Methods and Materials}

Rearing of Moths Galleria mellonella were obtained from laboratory cultures maintained at the Entomology Department, Cairo University (Egypt), and the Department of Biology, Ondokuz Mayıs University (Turkey). Last instar larvae were reared on honeycomb and kept at $\approx 23{ }^{\circ} \mathrm{C}, 60 \%$ r.h., and a 17:7 L:D photoperiod. Pupae were removed from cocoons, separated by sex, and placed in separate rooms under the same environmental conditions. One to 6-d-old moths were used in all experiments.

Headspace Collection and Extraction Headspace was collected from male and female $G$. mellonella $0-4 \mathrm{~h}$ into the scotophase, corresponding to the time of maximum sexual activity for this species (Nielsen and Brister 1977). Males and females, individually or in pairs, were placed in separate $50 \mathrm{ml}$ glass jars, with the opening covered with part of an oven bag (Toppits, Sweden). Collections were performed at $25^{\circ} \mathrm{C}$, $60 \%$ r.h., and $100 \mathrm{~lx}$ red light intensity. A Teflon filter, filled with $40 \mathrm{mg}$ of Tenax GR 60/80 (Alltech, PA, USA), and connected to a battery-driven air pump (GroTech, Sweden) via an aquarium hose, was inserted into the jar through a small hole in the oven bag. A second filter was inserted into an empty jar and served as a control to identify potential background contaminants. The flow rate of the pump was set to $200 \mathrm{ml} \mathrm{min}^{-1}$. Odor was collected for $2-3 \mathrm{~h}$, before the filter was eluted with $200 \mu \mathrm{l}$ of hexane containing methyl stearate $(10 \mathrm{ng} / \mu \mathrm{l})$ as internal standard for quantification. Prior to analysis, extracts were concentrated to $50 \mu \mathrm{l}$ under $\mathrm{N}_{2}$.

In addition to headspace collections, solvent extractions of different body parts of male and female G. mellonella were performed 1-3 $\mathrm{h}$ into the scotophase, so as to analyze whether the unknown electrophysiologically active compound (see below) was produced from the same tissue (the forewings) as the two aldehydes and their precursors. Forewings, hindwings, thorax, and abdomen of individual moths were extracted separately for $1 \mathrm{~h}$ in $100 \mu \mathrm{l}$ of hexane containing methyl stearate $(10 \mathrm{ng} / \mu \mathrm{l})$ as internal standard. These body extracts were analyzed in the same way as headspace samples (see below). Analysis of variance, followed by multiple comparisons, adjusted according to the Bonferroni post hoc test, were used to compare differences in the amounts of electrophysiologically active compounds found in different body parts, using SPSS Version 19 (SPSS Inc. Chicago, IL, USA). Total amounts of these compounds from individual males were calculated based on their gas chromatographic (GC) peak areas relative to that of the internal standard to enable preparation of stimuli for behavioral experiments (see below).

Electrophysiology The activity of compounds in headspace samples and extracts from male and female G. mellonella were examined by gas chromatography/electroantennographic detection (GC/EAD). Antennae from both sexes were used, with each preparation being used only for a single run. The head of a moth was cut, and the neck and both antennae mounted to a PRG-2 EAG (10× gain) probe (Syntech, Kirchzarten, Germany) using conductive gel (Blågel, Cefar, Malmö, Sweden). Charcoalfiltered and humidified air passed over the antennal preparation from a glass tube outlet, positioned $5 \mathrm{~mm}$ from the preparation. The GC effluent to the antennae passed through a heated transfer 
line, set at $230{ }^{\circ} \mathrm{C}$. Extracts, headspace samples, or a mixture of synthetic aldehydes $\left(\mathrm{C}_{8-11}\right)$, were injected into an Agilent $7890 \mathrm{~A}$ gas chromatograph (Agilent Technologies, Santa Clara, CA, USA), equipped with a polar HP-INNOWax column $(30 \mathrm{~m} \times$ $0.25 \mathrm{~mm}$ i.d., $0.25 \mu \mathrm{m}$ film thickness; J\&W Scientific, Agilent) or a less polar HP-5 column $(30 \mathrm{~m} \times 0.32 \mathrm{~mm}$ i.d., and $0.25 \mu \mathrm{m}$ film thickness; J\&W Scientific, Agilent). One microliter of sample was injected in splitless mode, with an injector temperature of $225^{\circ} \mathrm{C}$, and hydrogen as carrier gas at $30 \mathrm{~cm} \mathrm{sec}^{-1}$. A split at the end of the column allowed division of the GC effluent into two untreated columns leading to a flame ionization detector (FID) and the EAD. The oven temperature was maintained at $80^{\circ} \mathrm{C}$ for $2 \mathrm{~min}$. after injection, and then increased by $10{ }^{\circ} \mathrm{C} \min ^{-1}$ to $220^{\circ} \mathrm{C}$, with a final hold of $10 \mathrm{~min}$. Data were analyzed using the GC-EAD Pro Version 4.1 software (Syntech, Kirchzarten, Germany).

Gas Chromatography/Mass Spectrometry Analyses of EADActive Compounds Antennal-active compounds in headspace samples and extracts of male wax moths were identified using a Hewlett-Packard 5890II GC, coupled to an HP 5972 mass spectrometer (GC/MS), equipped with an HP-INNOWax column (as above). Helium was used as carrier gas at a velocity of $40 \mathrm{~cm} \mathrm{sec}^{-1}$, with an injector temperature of $220{ }^{\circ} \mathrm{C}$. After injection in splitless mode, the oven temperature was maintained at $50{ }^{\circ} \mathrm{C}$ for $2 \mathrm{~min}$ and then increased by $10^{\circ} \mathrm{C} \mathrm{min}{ }^{-1}$ to $250^{\circ} \mathrm{C}$, with a final hold of $10 \mathrm{~min}$. Aldehydes were identified using mass spectral libraries and by comparison with the retention times and mass spectra of synthetic standards. For the identification of the unknown bioactive compound in the extract (see below), additional GC/MS analyses were performed on a Hewlett-Packard 6890 N GC and an HP 5973 MS in full scan mode with electron impact (EI) ionization. The GC was equipped with a FactorFour VF-23 ms column (30 $\mathrm{m} \times 0.25 \mathrm{~mm}$ i.d., $0.25 \mu \mathrm{m}$ film thickness; J\&W Scientific, Agilent), with helium as carrier gas $\left(1 \mathrm{ml} \mathrm{min}^{-1}\right)$. Samples (each $1 \mu \mathrm{l}$ ) were injected in splitless mode, with the injector at $250{ }^{\circ} \mathrm{C}$, and the interface at $250{ }^{\circ} \mathrm{C}$. The oven temperature was increased by $10{ }^{\circ} \mathrm{C} \mathrm{min}^{-1}$ from 50 to $230{ }^{\circ} \mathrm{C}$, and kept at this temperature for $10 \mathrm{~min}$.

GC/IR Analysis of the EAD-Active Compound Gas Chromatography/Fourier Transform Infra Red spectroscopy (GC/FTIR) analysis of natural and synthetic compounds was carried out on a Thermo Scientific Nicolet 6700 FTIR spectrophotometer, coupled via an interface to an Agilent 7890A GC equipped with a FactorFour VF-23 ms column $(30 \mathrm{~m} \times$ $0.25 \mathrm{~mm}$ i.d., $0.25 \mu \mathrm{m}$ film thickness; J\&W Scientific, Agilent). The carrier gas was helium $\left(1 \mathrm{ml} \mathrm{min}^{-1}\right)$, with $1 \mu \mathrm{l}$ of sample injected in splitless mode at $250{ }^{\circ} \mathrm{C}$; the transfer line and flow cell temperatures were both set to $250{ }^{\circ} \mathrm{C}$. The oven temperature was increased from $50{ }^{\circ} \mathrm{C}$ by $10^{\circ} \mathrm{C} \mathrm{min} \operatorname{mo}^{-1}$ to $230{ }^{\circ} \mathrm{C}$ and held for $10 \mathrm{~min}$.
Purification of the EAD-Active Compound Whole body extract, obtained as mentioned above, was purified by liquid chromatography (LC) on a solid phase ( $\mathrm{SiOH})$ column using distilled cyclohexane as eluent. Early eluting fractions containing non-polar compounds were collected, pooled, and analyzed by GC and found to be $90 \%$ purity for the desired compound. After one more purification, via LC, the purity of the EAD-active compound increased to $95 \%$, and was then analyzed by nuclear magnetic resonance spectroscopy (NMR).

NMR Analysis of the Purified EAD-Active Compound ${ }^{1} \mathrm{H}$ NMR experiments of extracts and ${ }^{1} \mathrm{H}$ - and ${ }^{13} \mathrm{C}$ NMR experiments of synthetic standards were run at $298 \mathrm{~K}$ on a Bruker Avance $500\left({ }^{1} \mathrm{H} 500 \mathrm{MHz},{ }^{13} \mathrm{C} 125.8 \mathrm{MHz}\right)$ spectrometer using deuterated chloroform $\left(\mathrm{CDCl}_{3}\right)$ as solvent and tetramethylsilane (TMS) as internal standard. All chemical shifts are reported in ppm.

Chemicals Reference aldehydes $\left(\mathrm{C}_{8-11}\right)$ of purity $95-99 \%$ were purchased from PolyScience Corp. (Niles, IL, USA) and Aldrich Chemicals Ltd. (Dorset, England). The alkane reference compounds, 5,11-dimethylpentacosane and 5,14dimethylpentacosane, were synthesized at Mid Sweden University, Sundsvall, Sweden, as described below.

Synthesis General Dry THF was obtained from a solvent purification system (Activated alumina columns, Pure Solv PS-MD-5, Innovative technology, Newburyport, RI, USA) and ethanol (abs, $99.7 \%$ ) was dried over activated $3 \AA$ molecular sieves and used in the reactions when dry conditions were needed. All other chemicals and solvents were used as purchased from suppliers without further purification. LC was performed on normal-phase silica gel (Merck 60, 230$400 \mathrm{mesh}, 0.040-0.063 \mathrm{~mm}, 10-50 \mathrm{~g} / \mathrm{g}$ of product mixture) employing a gradient technique with an increasing concentration (0-100\%) of distilled ethyl acetate in distilled cyclohexane. Distillation of products under reduced pressure was performed in a bulb-to-bulb apparatus (Büchi-GKR-51). Thinlayer chromatography (TLC) was performed on silica gel plates (Merck 60, precoated aluminum foil) using ethyl acetate (40\%) in cyclohexane as eluent; plates were developed by ultraviolet irradiation and/or by spraying with vanillin in sulfuric acid, followed by heating at $120^{\circ} \mathrm{C}$.

Purities of products were checked and reactions monitored by GC using a Varian SATURN 2000 equipped with a split/ splitless injector, a FID (set at $280^{\circ} \mathrm{C}$ ), and an EC-1 capillary column (Alltech Associates, Inc. Deerfield, IL, USA, $30 \mathrm{~m} \times$ $0.32 \mathrm{~mm}$ i.d., $0.25 \mu \mathrm{m}$ film thickness, split ratio: 1:50). The injector was operated in split mode at $275^{\circ} \mathrm{C}$, and $\mathrm{N}_{2}$ was the carrier gas at $3 \mathrm{ml} \mathrm{min}^{-1}$. The oven temperature was maintained at $50{ }^{\circ} \mathrm{C}$ for $5 \mathrm{~min}$ and then increased by $10{ }^{\circ} \mathrm{C} \mathrm{min}{ }^{-1}$ to a final temperature of $300{ }^{\circ} \mathrm{C}$, which was kept for $5 \mathrm{~min}$. GC/ 
MS was run on an Agilent 7890 GC equipped with a polar capillary column (FactorFOUR vf-23 ms; J\&W Scientific, Agilent, $30 \mathrm{~m} \times 0.25 \mathrm{~mm}$ i.d., $0.25 \mu \mathrm{m}$ film thickness, split ratio of 1:20) coupled to an Agilent 240 ion trap MS. The injector was operated in split mode at $250{ }^{\circ} \mathrm{C}$, helium was used as carrier gas with a flow rate of $1 \mathrm{ml} \mathrm{min}^{-1}$, and the transfer line temperature was set to $280^{\circ} \mathrm{C}$. Oven temperature was increased from $50^{\circ} \mathrm{C}$ by $10^{\circ} \mathrm{C} \cdot \mathrm{min}^{-1}$ to $230^{\circ} \mathrm{C}$ and kept at this temperature for $10 \mathrm{~min}$. EI spectra were recorded over $\mathrm{m} / \mathrm{z}$ $50-300$ at a fast scan rate.

5,11-Dimethylpentacosane Nonane-2,8-dione: A suspension of 1,8-nonadiene ( $2 \mathrm{~g}, 16 \mathrm{mmol}), \mathrm{PdCl}_{2}(10 \mathrm{~mol} \%, 0.29 \mathrm{~g}$, $1.64 \mathrm{mmol}), \mathrm{Cu}(\mathrm{OAc})_{2} \times \mathrm{H}_{2} \mathrm{O}(20 \mathrm{~mol} \%, 0.65 \mathrm{~g}, 3.23 \mathrm{mmol})$, dimethylacetamide $(20 \mathrm{ml})$, and water $(3 \mathrm{ml})$ was stirred in an atmosphere of oxygen for $48 \mathrm{~h}$. The mixture was diluted with $\mathrm{Et}_{2} \mathrm{O}$ and filtered through Celite (Sigma-Aldrich). The filtrate was diluted with $\mathrm{H}_{2} \mathrm{O}$, extracted with $\mathrm{Et}_{2} \mathrm{O}$, dried over $\mathrm{MgSO}_{4}$, and the solvent evaporated. The crude product was purified by LC and distillation, under reduced pressure, to give pure (according to GC) diketone as a clear oil (1.7 g, $10.9 \mathrm{mmol})$. Analytical data were similar to Tachinami et al. (2013).

8-Methyldocos-8-en-2-one: $n$-Tetradecyl triphenyl phosphonium bromide $(3.12 \mathrm{~g}, 5.8 \mathrm{mmol})$ was dried in argon atmosphere and dissolved in dry THF $(20 \mathrm{ml})$. tertButyllithium (1.7 M in pentane, $3.6 \mathrm{ml}, 6.1 \mathrm{mmol}$ ) was added dropwise to the mixture to generate the ylide. After $1 \mathrm{~h}$, the solution of nonane-2,8-dione $(0.88 \mathrm{~g}, 5.6 \mathrm{mmol})$ in THF $(10 \mathrm{ml})$ was added to the reaction flask and left to react for $6 \mathrm{~h}$. The reaction mixture was quenched with water, extracted with $\mathrm{Et}_{2} \mathrm{O}(4 \times 40 \mathrm{ml})$, washed with brine, dried with $\mathrm{Na}_{2} \mathrm{SO}_{4}$, and the solvent evaporated. LC of the crude product gave the pure title compound $(0.365 \mathrm{~g}, 1.19 \mathrm{mmol})$ that was used directly for the next reaction after control of the identity by ${ }^{1} \mathrm{H}$ NMR.

5,11-Dimethylpentacosa-4,11-diene: The procedure for the Wittig-reaction was repeated as above but using 8 methyldocos-8-en-2-one and $n$-butyl triphenyl phosphonium bromide. Purification of the crude product was done by LC using cyclohexane as eluent and resulted, according to GC, in a pure 1:1:1:1 mixture of four stereoisomers of 5,11dimethylpentacosa-4,11-diene ( $0.07 \mathrm{~g}, 0.19 \mathrm{mmol})$. After confirmation of identity by ${ }^{1} \mathrm{H}$ NMR, the diene was used in the next reaction.

5,11-Dimethylpentacosane: The diene from above $(0.07 \mathrm{~g}$, $0.186 \mathrm{mmol}$ ) was dissolved in ethanol (abs) and added to a solution of $\mathrm{Pd} / \mathrm{C}(10 \mathrm{wt} . \% \mathrm{Pd}$ on activated carbon, $0.60 \mathrm{~g}$ ) in ethanol (abs) under argon pressure (1 atm). The argon was evacuated and replaced by $\mathrm{H}_{2}$ and the suspension was left stirring under $\mathrm{H}_{2}$-pressure $(1 \mathrm{~atm})$ for $48 \mathrm{~h}$. The mixture then was filtered from $\mathrm{Pd} / \mathrm{C}$ and washed with several portions of ethanol (abs). After evaporation, the crude 5,11- dimethylpentacosane was purified by $\mathrm{LC}$, yielding the title compound as a clear oil $(0.025 \mathrm{~g}, 0.07 \mathrm{mmol}, 95 \%$ purity according to GC). See Supplementary Material for complete spectra. ${ }^{1} \mathrm{H}$ NMR: $\delta 0.84(3 \mathrm{H}, \mathrm{d}, J=6.6 \mathrm{~Hz}), 0.84(3 \mathrm{H}, \mathrm{d}, J=$ $6.6 \mathrm{~Hz}), 0.88(3 \mathrm{H}, \mathrm{t}, J=6.9 \mathrm{~Hz}), 0.89(3 \mathrm{H}, \mathrm{t}, J=6.9 \mathrm{~Hz}), 1.04$ $1.10(4 \mathrm{H}, \mathrm{m}), 1.20-1.40\left(40 \mathrm{H}, \mathrm{m}\right.$ and bs). ${ }^{13} \mathrm{C} \mathrm{NMR} ; \mathrm{CDCl}_{3}$ : $\delta 14.28,14.33,19.89,19.89,22.85,23.21,27.25,27.27$, $27.27,29.50,29.52,29.82,29.86,29.86,29.86,29.86$, $29.86,29.89,30.19,30.53,32.08,32.90,32.90,36.94$, 37.25, 37.25, 37.25. GC-FTIR: $2932(\mathrm{C}-\mathrm{H}), 2862(\mathrm{C}-\mathrm{H})$ $\mathrm{cm}^{-1}$. MS: $m / z 380\left(\mathrm{M}^{+},<1\right), 323$ (19), 224 (20), 183 (26), 113 (21), 99 (32), 85 (94), 71 (83), 57 (100), 43 (77).

5,14-Dimethylpentacosane This was prepared as above for 5,11-dimethylpentacosane, but using 1,11-dodecadiene, and was used as a reference standard for structure elucidation of the unknown EAD-active compound in extracts of G. mellonella.

Flight Tunnel Experiments A $0.9 \times 0.9 \times 3 \mathrm{~m}$ Plexiglas flight tunnel was used to evaluate the behavioral responses of female G. mellonella to synthetic EAD-active compounds and to male whole body extract. At least $2 \mathrm{~h}$ before the beginning of the scotophase, 1-6-d-old virgin females were transferred to the flight tunnel room to acclimate to the conditions, and placed individually in glass cylinders $(98 \times 22 \mathrm{~mm}$ i.d.). Bioassays were conducted $2-4 \mathrm{~h}$ into the scotophase at $5 \mathrm{~lx}, 21-$ $24{ }^{\circ} \mathrm{C}$ and $50-75 \%$ r.h., with airflow in the tunnel set at $0.3 \mathrm{~m} \mathrm{sec}^{-1}$. An odor stimulus was prepared by pipetting $10 \mu \mathrm{l}$ of a test solution onto a small strip of filter paper, which was attached with an insect pin to a $30 \mathrm{~cm}$-high metal holder placed at the upwind end of the flight tunnel. The filter paper was replaced and a new stimulus added for each new female tested. One min. was allowed for the hexane to evaporate prior to the initiation of a flight experiment. Before being allowed to take off from the cylinder, each female was exposed to the odor plume at the downwind end of the flight tunnel for at least $10 \mathrm{sec}$.

Preliminary trials using male extract revealed that G. mellonella females did not orient as quickly within the odor plume and took a longer time to reach the odor source compared to what we have observed for males of other moth species tested to female-produced sex pheromones in the same flight tunnel (e.g., Svensson et al. 2004). Thus, in subsequent experiments, each female was given $10 \mathrm{~min}$. to respond to an odor stimulus. Each moth was only used once, and those not able to fly properly (in total, four females) were excluded from the analysis. The following test stimuli were used, each corresponding to 0.1 male equivalents: (i) $2 / 7 \mathrm{ng}$ of nonanal/ undecanal, (ii) $54 \mathrm{ng}$ of 5,11-dimethylpentacosane, (iii) 2/7/ $54 \mathrm{ng}$ of nonanal/undecanal/5,11-dimethylpentacosane, and (iv) a male whole-body extract with similar amounts of compounds as for the three-component blend. During flight tests, 
four different behaviors of female moths were scored: take flight, initiating orientation in the odor plume, upwind flight in the plume halfway to the odor source, and contacting the odor source. Flight responses to different test stimuli were compared using $\chi^{2}$-statistics in Excel Version 14.3.8 for Mac users (C) 2010 Microsoft Corporation).

\section{Results}

Electrophysiology Antennal recordings using a male headspace sample as stimulus were obtained from nine females and four males. Three compounds elicited antennal responses in all females tested: nonanal and undecanal, and an unknown compound with a much longer retention time (Fig. 1a). Decanal (a typical contaminant) elicited antennal responses in six of the females tested. Antennae of males also responded to these four compounds, with no apparent sexual dimorphism in the response profiles of G. mellonella to male scent compounds. Antennal sensitivity to nonanal, decanal, and undecanal was confirmed by using synthetic standards as stimuli, whereas octanal did not elicit any response (Fig. 1b).

\section{Analysis of Headspace Samples and Gland Extracts Similar} to that reported by Romel et al. (1992), headspace samples of male G. mellonella contained large amounts of nonanal and undecanal, as well as much smaller amounts of the corresponding primary alcohols and fatty acids (data not shown). In addition, a small amount of an unknown EAD-active compound was detected in all male samples. The aldehydes, primary alcohols, and fatty acids were repeatedly found in male extracts, but never in female extracts. Solvent extracts of males, but not of females, also contained large amounts of the unknown EAD-active compound, ultimately leading to its identification as 5,11-dimethylpentacosane (see below). The analysis of different male body parts showed, as expected, that the total amounts of nonanal and undecanal were higher in forewings compared to other tissues (Anova; $P<0.001$; Fig. 2). In contrast, the amount of 5,11-dimethylpentacosane did not differ among body parts (Fig. 2), indicating that this compound may be produced independently from the aldehydes.

Identification of 5,11-Dimethylpentacosane as an EAD-Active Compound A structure of the EAD-active compound in the crude extract of $G$. mellonella was proposed after analysis by GC/MS and GC/FTIR, followed by ${ }^{1} \mathrm{H}$ NMR analysis of the LC-purified active hydrocarbon. The structure was confirmed by synthesis and comparison of reference compounds. The mass spectrum (Fig. 3a) showed a base peak of $m / z 57$, with dominant peak clusters, typical of alkanes, around $m / z 14 \mathrm{n}+1$. A very weak molecular ion $\left[\mathrm{M}^{+}\right]$at $\mathrm{m} / z 380$ was observed, consistent with the formula $14 n+2$, where $n=27$ carbon atoms. Low abundance of the molecular ion typically is caused by branching of the carbon chain of an alkane and $m / z=365$ indicated methyl branching in the chain. Fragment ions $\mathrm{C}_{6} \mathrm{H}_{13}{ }^{+} m / z=85$ (93\%), $\mathrm{C}_{13} \mathrm{H}_{27}{ }^{+} m / z=183, \mathrm{C}_{16} \mathrm{H}_{32}{ }^{+}$ $\mathrm{m} / \mathrm{z}=224(21 \%)$ and $\mathrm{C}_{23} \mathrm{H}_{47}{ }^{+} \mathrm{m} / \mathrm{z}=323$ probably result from fragmentation next to methyl branches giving more stable secondary ions of increased abundance (Fig. 3a).

Steinmetz et al. (2003) analyzed cuticular extracts and trails of workers of Vespula vulgaris L. These gave diagnostic ions for several similar hydrocarbons, among them 5,11dimethylpentacosane, as $m / z 365,84 / 85,323,182 / 183$, and $224 / 225$. This is in good agreement with the mass spectrum of the GC/EAD active compound in the extract (Fig. 3a) and our
Fig. 1 Simultaneous responses of flame ionization (FID) and electroantennographic (EAD) detection using antennae of a female Galleria mellonella to: a headspace sample of a conspecific male, and $\mathbf{b}$ synthetic aldehydes of different chain length. Decanal is a common background contaminant from headspace collections, and was not present in extracts of males. An HP-5 capillary column was used

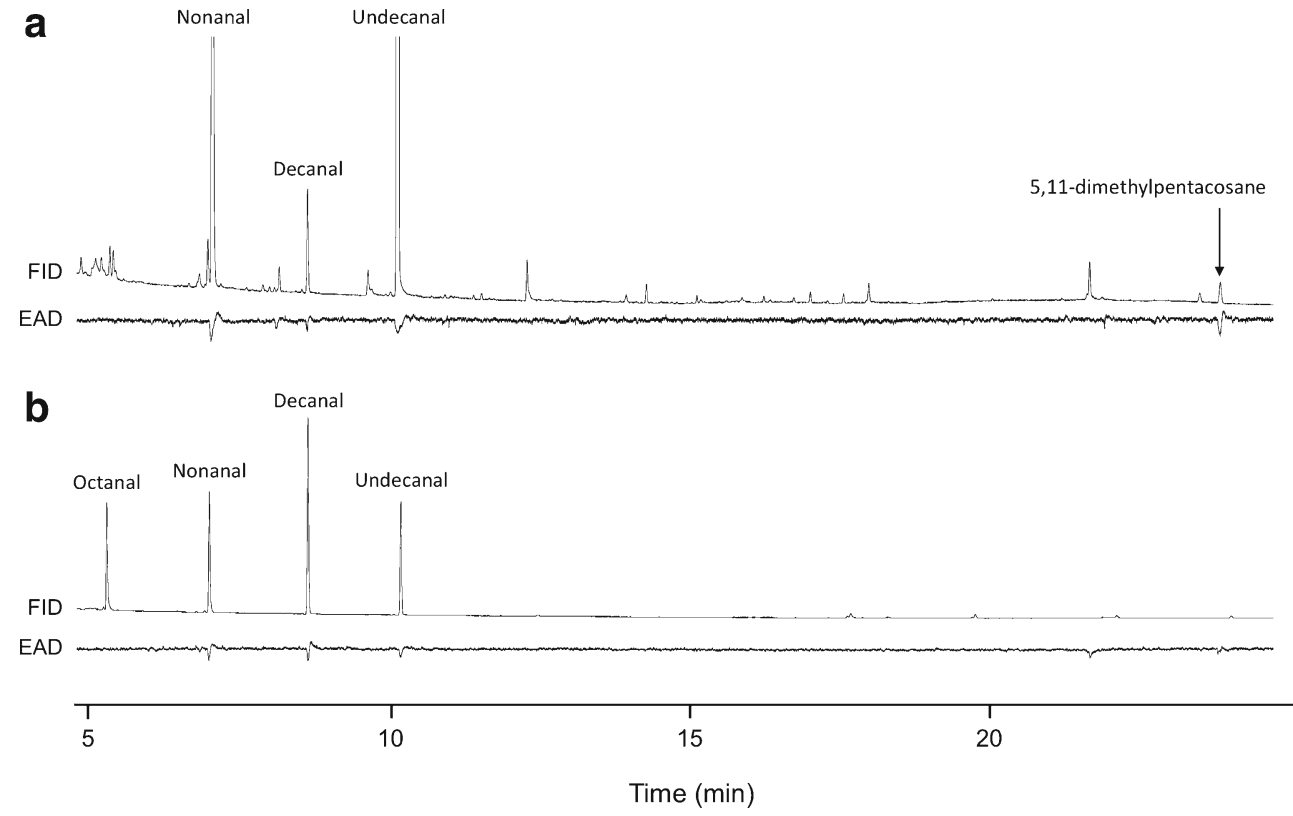



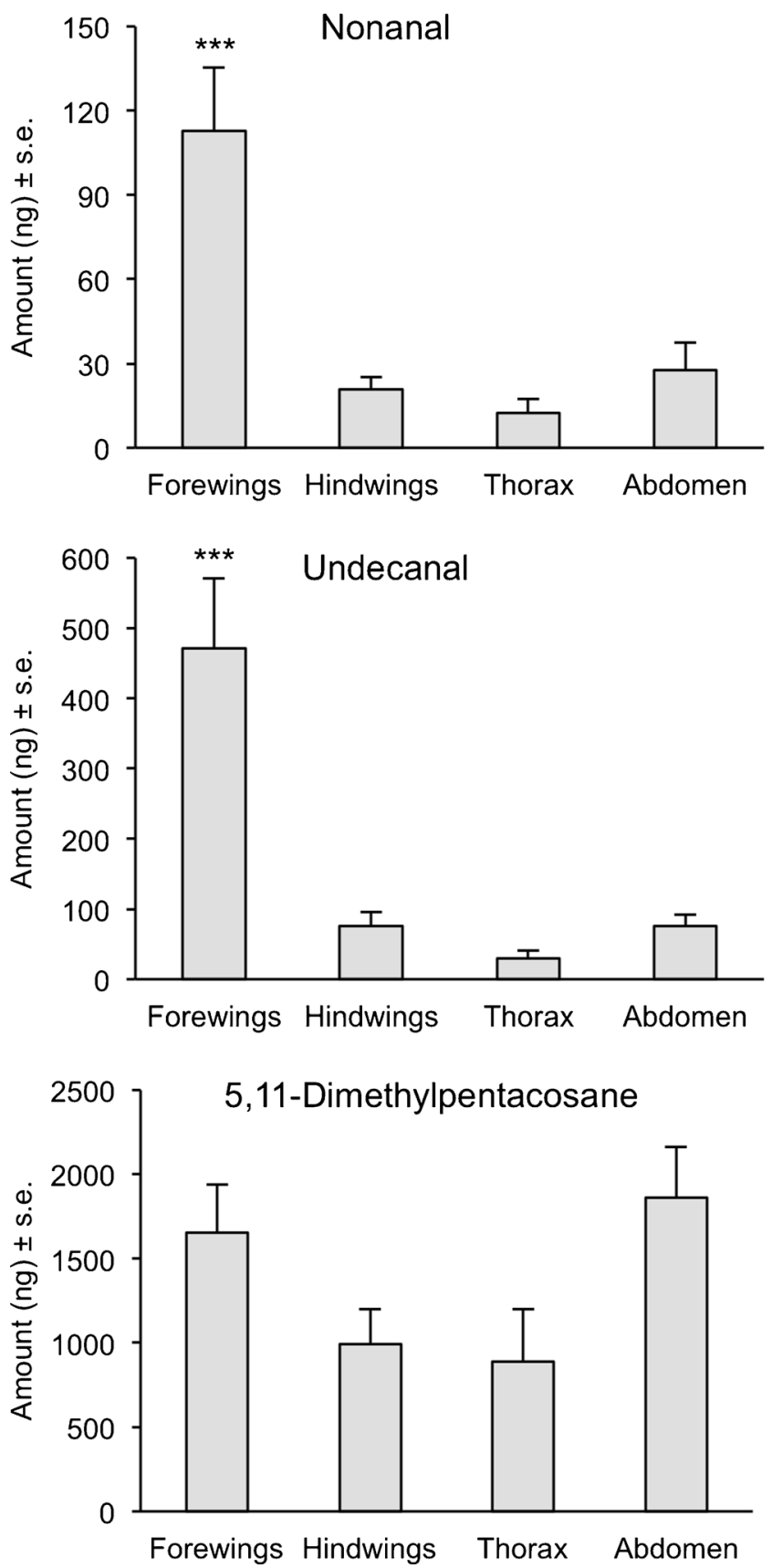

Fig. 2 Amounts per individual of three electrophysiologically active compounds in different body parts of male Galleria mellonella. Amounts of compounds from different body parts were compared using one-way ANOVA followed by multiple comparisons according to the Bonferroni posthoc test $(* * * P<0.001)$

interpretation of the MS data. All these data allowed us to narrow the structure to either 5,11-dimethylpentacosane or 5,14-dimethylpentacosane, both having the same diagnostic ions. The GC/FTIR analysis (see spectra in Supplementary Material) of the unknown compound in the extract gave some valuable information, as the spectrum did not show any absorptions indicating the presence of a heteroatom, aromatic or alkene group. An intense absorption at $2932 \mathrm{~cm}^{-1}$ and a a
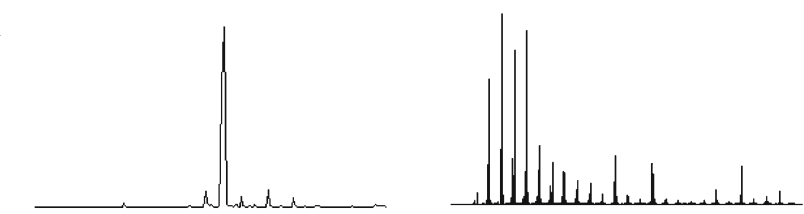

b
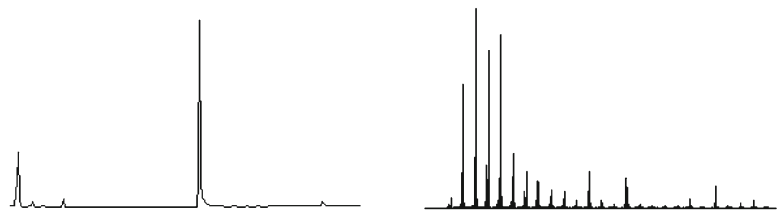

C
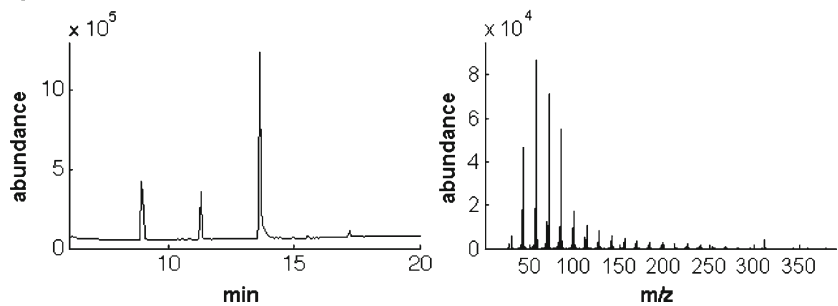

Fig. 3 Gas chromatograms and mass spectra of: a the EAD-active hydrocarbon in extract of male Galleria mellonella; b synthetic 5,11dimethylpentacosane; and $\mathbf{c}$ synthetic 5,14-dimethylpentacosane

medium intensity absorption at $2864 \mathrm{~cm}^{-1}$ reinforced the suggestion that the bioactive compound was a hydrocarbon.

After LC purification of extract, the ${ }^{1} \mathrm{H}$ NMR spectrum for the EAD-active compound was found to have signals only in the upfield region below $1.4 \mathrm{ppm}$ (Fig. 4a shows the up-field part of the spectrum and the full spectrum is provided as Supplementary
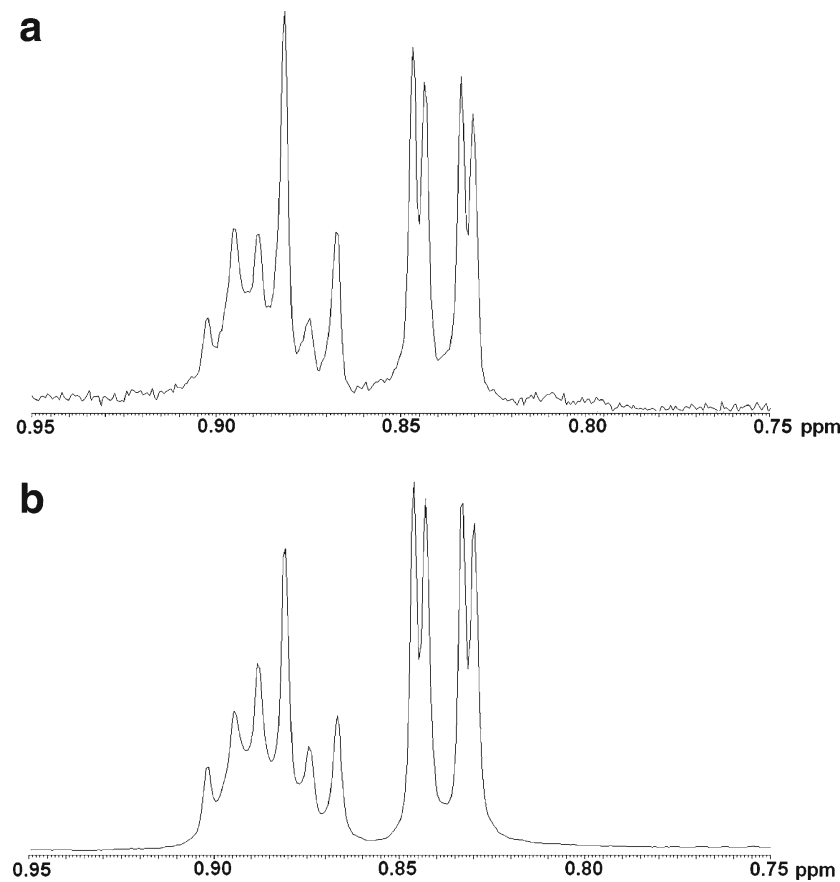

Fig. 4 Expanded methyl group region of the ${ }^{1} \mathrm{H}$ NMR spectrum of: a the EAD-active hydrocarbon in extract of male Galleria mellonella, and $\mathbf{b}$ synthetic 5,11-dimethylpentacosane 
Material). Characteristics for methyl, methylene, and methine groups confirmed that the structure was an alkane. Important information about the structure was obtained looking closely at the most up-field region of the spectrum, with two doublets at $0.8395 \mathrm{ppm}(J=6.55 \mathrm{~Hz})$ and $0.8363(J=6.55 \mathrm{~Hz})$. The doublets originate from two slightly different methyl groups coupled to one $\mathrm{CH}$ proton each in the carbon chain (Fig. 4a). From this, we concluded that the structure contained two methyl branches. The two overlapping triplet signals at $0.8875 \mathrm{ppm}(J=7 \mathrm{~Hz})$ and $0.8809 \mathrm{ppm}(J=6.65$ and $7.52 \mathrm{~Hz})$ belonged to protons of two terminal methyl groups that are coupled to two identical neighboring protons each (Fig. 4a). Four methylene protons were observed as a broad multiplet at $1.13-1.03 \mathrm{ppm}$, and these are probably protons of the two $\mathrm{CH}_{2}$ groups coupled with terminal methyl groups. The remaining methylene protons of the molecule were observed as an intense multiplet at $1.31-1.17 \mathrm{ppm}$, which partly overlapped with a multiplet at $1.40-1.32 \mathrm{ppm}$ of two methine protons.

Based on the above analyses, we decided to synthesize 5,11dimethylpentacosane and 5,14-dimethylpentacosane for comparison with the EAD-active compound. Thus, 5,11dimethylpentacosane was synthesized from nona-1,8-diene in four steps (Fig. 5) and 5,14-dimethylpentacosane similarly, starting from 1,11-dodecadiene (Fig. 5). GC/MS data for synthetic 5,11-dimethylpentacosane and 5,14-dimethylpentacosane are shown in Fig. 3b, c, respectively (see also Supplementary Material for more GC/MS data). It is apparent that the mass spectrum of 5,11-dimethylpentacosane is identical with that of the EAD-active compound (Fig. 3a) in the extract, and that the mass spectrum of 5,14-dimethylpentacosane is not. ${ }^{1} \mathrm{H}$ NMR analysis of 5,11-dimethylpentacosane also revealed a spectrum consistent with that of the EAD-active compound (see Fig. 4b and Supplementary Material for ${ }^{1} \mathrm{H}$ NMR data). Thus, we concluded that the unknown compound was chemically identical with 5,11-dimethylpentacosane. This compound was subsequently used in the bioassay.

Flight Tunnel Experiments When tested alone, the aldehyde blend and 5,11-dimethylpentacosane triggered wing-fanning in most females tested, but these stimuli failed to elicit additional sexual behaviors, such as upwind orientation in the odor plume. In fact, only one out of 20 females exposed to the aldehyde blend showed robust odor-mediated upwind flight halfway to the source, and not a single female out of 20 tested to 5,11-dimethylpentacosane showed this behavior (Fig. 6). No females reached the odor source in any of these experiments. However, when a combination of aldehydes and 5,11dimethylpentacosane was used as a stimulus, all females initiated upwind flight in the odor plume, $75 \%$ oriented in the odor plume halfway to the source, and $30 \%$ reached the odor source, generally followed by heavy wing-fanning on the filter paper for several minutes. Although the 3-component blend was more attractive to females than the aldehyde blend or the 5,11-dimethylpentacosane $\left(\chi^{2}=7.06 ; d f=1 ; P<0.01\right.$ for both comparisons) alone, it was less attractive compared to male extract, for which $70 \%$ of the females reached the source $\left(\chi^{2}=6.40 ; d f=1 ; P<0.05\right)$. When females were exposed to male extract, which is presumably optimal, their orientation
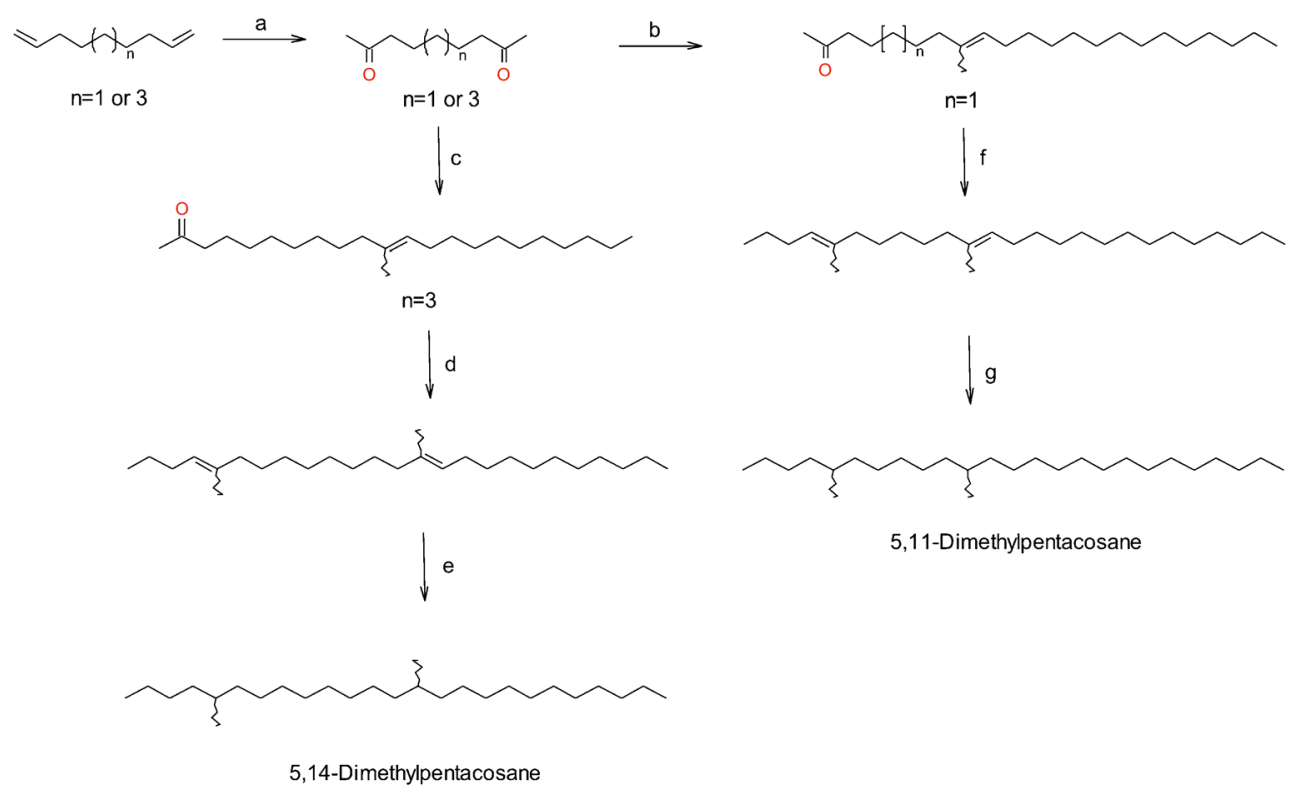

butyl triphenyl phosphonium bromide and 8-methyldocos-8-en-2-one; $\mathbf{d}$

Fig. 5 Synthetic route for 5,11-dimethylpentacosane and 5,14dimethylpentacosane, used in the identification of the unknown EADactive component in extract of male Galleria mellonella: a 1,8-nonadiene $(n=1)$ or 1,11-dodecadiene $(n=3), \mathrm{PdCl}_{2}, \mathrm{Cu}(\mathrm{OAc})_{2}$, dimethylacetamide, $\mathrm{H}_{2} \mathrm{O}, \mathrm{O}_{2}, 48 \mathrm{~h} ; \mathbf{b} n$-tetradecyl triphenyl phosphonium bromide, dry THF, tert-butyllithium, $1 \mathrm{~h}$, then nonane-2,8-dion, $6 \mathrm{~h}$; $\mathbf{c}$ as for (b), but from $n$ -

$\mathrm{Pd} / \mathrm{C}$, ethanol, $\mathrm{H}_{2}, 48$; e as for (b), but from $n$-undecyl triphenyl phosphonium bromide and undecane-2,10-dione; $\mathbf{f}$ as for (c), but from $n$-butyl triphenyl phosphonium bromide and 11-methyldocos-11-en-2-one; $\mathbf{g}$ as for (d) 


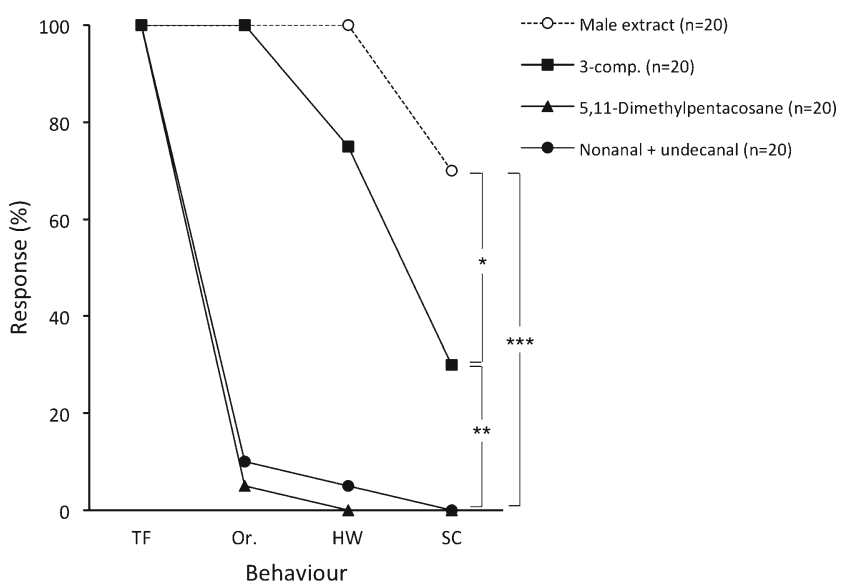

Fig. 6 Behavioral responses to different olfactory stimuli in wind tunnel tests with female Galleria mellonella ( $T F$ take flight, $O r$. initiating orientation in the odor plume, $H W$ upwind flight in the plume halfway to the odor source, $S C$ contacting the odor source). Percentages of females contacting the different odor sources were compared using $\chi^{2}$-statistics $\left({ }^{*} P<0.05 ; * * P<0.01 ; * * * P<0.001\right)$

behavior appeared similar to that which is typically observed when male moths are tracking suboptimal pheromones plumes; i.e., extended flights back and forth across the wind direction, with limited upwind progress. On many occasions, females lost the plume several times during the tracking process.

\section{Discussion}

We identified a third male-produced pheromone component in G. mellonella: the long-chain hydrocarbon 5,11dimethylpentacosane. The presence of this compound in a blend was essential for triggering typical pheromonemediated upwind flight of conspecific females in our wind tunnel bioassay. When exposed to a blend of the previously identified pheromone components, nonanal and undecanal, or 5,11-dimethylpentacosane alone, very few females showed any behavioral response, whereas all females exposed to the combination of aldehydes and the hydrocarbon initiated upwind orientation (Fig. 6). In contrast to earlier behavioral studies on $G$. mellonella, in which very large amounts of the aldehydes were used (Flint and Merkle 1983), we used more realistic doses ( 0.1 male equivalents of each compound) in our bioassay. Although the 3-component blend was more attractive to females than the aldehyde blend or 5,11dimethylpentacosane alone, it was still less attractive than male extract, indicating that the identification of the $G$. mellonella sex pheromone is not yet complete.

The compound 5,11-dimethylpentacosane has previously been identified from chemical trails of $V$. vulgaris (Steinmetz et al. 2003), as well as on the cuticle of the ant species Myrmica rubra L. (Bagnères and Morgan 1990) and Melipona bicolor
Lepeletier (Abdalla et al. 2003). To our knowledge, however, our study is the first to confirm behavioral activity of 5,11dimethylpentacosane in a natural system, and the first to provide information about the synthesis of the compound. Although dimethylpentacosanes are considered non-volatile, our headspace analyses show that 5,11-dimethylpentacosane is released from male moths, and in our flight tunnel it functioned as a critical component for attraction of female $G$. mellonella over several meters. Whereas nonanal and undecanal are released from specialized forewing glands of male $G$. mellonella (Romel et al. 1992), our analysis of extracts from different male body parts did not detect any differences among tissues regarding the amount of 5,11-dimethylpentacosane (Fig. 2). In insects, oenocytes are the primary site for production of methylalkanes and other hydrocarbons (Lockey 1988). Thus, 5,11dimethylpentacosane is probably produced via a different biosynthetic pathway from that of the aldehydes.

The observed orientation behavior of female G. mellonella tracking plumes of the male-produced sex pheromone was not as straight and fast as what is typically observed for male moths navigating in plumes of female-produced sex pheromones. In our experiments, female moths often performed extended zigzagging flight within the odor plume and frequently left the plume, behaviors that are associated with male flight behaviors in pheromone plumes of suboptimal quality (Witzgall 1997). Although all females tested against the male extract exhibited orientation in the plume halfway to the source, many individuals lost the plume repeatedly when approaching the source. Because Galleriinae moths are known to use a combination of olfactory and auditory cues during mate searching (Dahm et al. 1971; Kindl et al. 2011; Spangler 1986, 1987), the lack of any sound stimulation during the flight experiments may explain the relatively poor behavioral performance of females in this study. The dependence of multimodal stimuli may have implications when designing an efficient trapping system for pest species of Galleriinae moths.

Although the identification of 5,11-dimethylpentacosane as a pheromone component of $G$. mellonella is an important step toward the development of efficient odor-based monitoring and control of this pest species, there are still several aspects that remain to be determined regarding the composition of the sex pheromone. First, our behavioral experiments revealed that the 3component blend was less efficient in attracting female moths than was male extract, suggesting that the composition of the multi-component blend was suboptimal, or that additional pheromone components are still to be identified. Second, the stereochemistry of the 5,11-dimethylpentacosane produced by male wax moths was not determined. There are four possible stereoisomers of this compound and our synthesis likely produced all of them in equal amounts, which means that as none of the isomers seemed to shut down attraction (at least completely), a 1:1:1:1 stereoisomeric mixture can be used for monitoring 
purposes. However, it is possible that a specific stereoisomeric composition is required for maximal activity. The fact that we used a 1:1:1:1 stereoisomeric mixture of 5,11dimethylpentacosane is one possible explanation for the lower activity obtained with our 3-component blend compared to male extract. In addition, the site of production and the biosynthesis of 5,11-dimethylpentacosane are unknown. Thus, further studies are needed to elucidate fully the chemical ecology of $G$. mellonella and to improve strategies for population monitoring and control of this widespread pest.

Acknowledgments We thank Hany Dweck for sending moth larvae, Dr Palle Breistein for part of the syntheses of pentacosanes, and Dr Joakim Bång for purification of moth extracts and some initial GC/MS analyses. Jon Loman provided wax cakes for the last instar larvae. This study was supported by a joint research grant under the Middle East and North Africa - Swedish Research Links Program to EAG and OA, and from grants by The Swedish Research Council (VR) and Birgit and Sven Håkan Ohlsson foundation to CL. NS and EH are grateful for the financial support from the European Union European Regional Development Fund and the County Administrative Board of Västernorrland.

\section{References}

Abdalla FC, Jones GR, Morgan ED, Cruz-Landim C (2003) Comparative study of the cuticular hydrocarbon composition of Melipona bicolor Lepeletier, 1836 (Hymenoptera, Meliponini) workers and queens. Genet Mol Res 2:191-199

Bagnères AG, Morgan ED (1990) A simple method for analysis of insect cuticular hydrocarbons. J Chem Ecol 16:3263-3276

Birch MC, Poppy GM, Baker TC (1990) Scents and eversible scent structures of male moths. Annu Rev Entomol 35:25-58

Dahm KH, Meyer D, Finn WE, Reinhold V, Röller H (1971) The olfactory and auditory mediated sex attraction in Achroia grisella (Fabr.). Naturwissenschaften 58:265-266

Flint HM, Merkle JR (1983) Mating behaviour, sex pheromone responses and radiation sterilization of the greater wax moth (Lepidoptera: Pyralidae). J Econ Entomol 76:467-472

Kalinová B, Kindl J, Jiroš P, Žáček P, Vašičková S, Buděšínský M, Valterová I (2009) Composition and electrophysiological activity of constituents identified in male wing gland secretion of the bumblebee parasite Aphomia sociella. J Nat Prod 72:8-13
Kindl J, Kalinová B, Červenka M, Jílek M, Valterová I (2011) Male moth songs tempt females to accept mating: the role of acoustic and pheromonal communication in the reproductive behaviour of Aphomia sociella. PLoS One 6(10):e26476

Lassance JM, Löfstedt C (2009) Concerted evolution of male and female display traits in the European corn borer, Ostrinia nubilalis. BMC Biol 7:10

Leyrer RL, Monroe RE (1973) Isolation and identification of the scent of the moth, Galleria melonella, and a reevaluation of its sex pheromone. J Insect Physiol 19:2267-2271

Lockey KH (1988) Lipids of the insect cuticle: origin, composition and function. Comp Biochem Physiol 89B:595-645

Nielsen RA, Brister CD (1977) The Greater wax moth: adult behavior. Ann Entomol Soc Am 70:101-103

Nielsen RA, Brister CD (1979) Greater wax moth: behaviour of larvae. Ann Entomol Soc Am 72:811-815

Payne TL, Finn WE (1977) Pheromone receptor system in the females of the greater wax moth Galleria mellonella. J Insect Physiol 23:879881

Phelan LP (1997) Evolution of mate-signaling in moths: Phylogenetic considerations and predictions from the asymmetric tracking hypothesis. In: Choe JC, Crespi BJ (eds) The evolution of mating systems in insects and arachnids. Cambridge University Press, Cambridge, pp 240-256

Romel KE, Scott-Dupree CD, Carter MH (1992) Qualitative and quantitative analyses of volatiles and pheromone gland extracts collected from Galleria mellonella (L.) (Leptidoptera: Pyralidae). J Chem Ecol 18:1255-1268

Schmidt SP, Monroe RE (1976) Biosynthesis of the waxmoth sex attractants. Insect Biochem 6:377-380

Spangler HG (1986) Functional and temporal analysis of sound production in Galleria mellonella (Lepidoptera: Pyralidae). J Comp Physiol A 159:751-756

Spangler HG (1987) Acoustically mediated pheromone release in Galleria mellonella (Lepidoptera: Pyralidae). J Insect Physiol 7: 465-468

Steinmetz I, Schmolz E, Ruther J (2003) Cuticular lipids as trail pheromone in a social wasp. Proc R Soc Lond B 270:385-391

Svensson GP, Löfstedt C, Skals N (2004) The odour makes the difference: male moths attracted by sex pheromones ignore the threat from predatory bats. Oikos 104:91-97

Tachinami T, Nishimura T, Ushimaru R, Noyori R, Naka H (2013) Hydration of terminal alkynes catalyzed by water-soluble cobalt porphyrin complexes. J Am Chem Soc 135:50-53

Witzgall P (1997) Modulation of pheromone-mediated flight in male moths. In: Cardé RT, Minks A (eds) Insect pheromone research: New directions. Chapman and Hall, New York, pp $248-264$ 